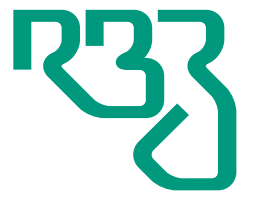

\section{Revista}

Brasileira de

Zootecnia

Brazilian Journal of Animal Science

ISSN 1806-9290

www.rbz.org.br

\title{
Inbreeding depression in Holstein cattle in Brazil
}

\author{
Mário Henrique Magalhães Araújo da Silva ${ }^{1}$ (iD, Carlos Henrique Mendes \\ Malhado² $^{2}$ iD, Elisandra Lurdes Kern ${ }^{3}$ (iD, Darlene dos Santos Daltro ${ }^{4}$ (iD), \\ Jaime Araujo Cobuci ${ }^{{ }^{*}}$ (iD, Paulo Luiz Souza Carneiro² ${ }^{2}$ iD \\ ${ }^{1}$ Universidade Estadual do Sudoeste da Bahia, Programa de Pós-Graduação em Zootecnia, \\ Itapetinga, BA, Brasil. \\ ${ }^{2}$ Universidade Estadual do Sudoeste da Bahia, Departamento de Ciências Biológicas, Jequié, \\ BA, Brasil. \\ ${ }^{3}$ Universidade Estadual do Oeste do Paraná, Departamento de Zootecnia, Marechal Cândido \\ Rondon, PR, Brasil. \\ ${ }^{4}$ Universidade Federal do Rio Grande do Sul, Programa de Pós-Graduação em Zootecnia, \\ Porto Alegre, RS, Brasil. \\ ${ }^{5}$ Universidade Federal do Rio Grande do Sul, Departamento de Zootecnia, Porto Alegre, \\ RS, Brasil.
}

ABSTRACT - The objective of this study was to evaluate inbreeding depression in Holstein cows in Brazil, considering their 305-day milk production (MP), age of first calving (AFC), and calving interval (CI). The effects of inbreeding depression on the traits were determined using four regression models (linear, quadratic, exponential, and Michaelis-Menten) about the errors generated by the animal model. The linear model was significant for $\mathrm{CI}$, and the quadratic model was significant for $\mathrm{CI}$ and $\mathrm{AFC}$. The Michaelis-Menten and exponential models were significant for MP, AFC, and CI. Inbreeding depression affected MP and CI. Cows with inbreeding coefficient of $15 \%$ produced approximately $260 \mathrm{~kg}$ less milk than non-inbred cows. A $1 \%$ increase in the inbreeding level resulted in an unfavorable increase of $\mathrm{CI}$ of 1.88 days. The quadratic and exponential models showed no variations for CI with increasing inbreeding level; however, the Michaelis-Menten model showed a positive effect of inbreeding on CI. Despite of the small number of inbred Holstein cows, the inbreeding negatively affected milk production and calving intervals. Therefore, breeders should monitor their cattle inbreeding levels. The Michaelis-Menten and exponential non-linear models are best suited to fit inbreeding data of Holstein cows.

\section{Introduction}

Inbreeding is the production of offspring from the breeding of individuals that are closely related genetically. It leads to loss of genetic variability and increased frequency of undesirable deleterious alleles; as a result, it may cause reproduction and production problems in animals (Croquet et al., 2007). The hypothesis of partial dominance shows that inbreeding increases the frequency of homozygotes; thus, inbreeding depression is caused by the expression of deleterious recessive alleles in homozygous individuals (Jones, 1917; Croquet et al., 2007).

The technology used in breeding programs has generated significant genetic advances for traits of economic interest (Sørensen et al., 2005). However, the intensive use of few bulls for breeding, 
combined with selection methods using family information, such as the best linear unbiased prediction, has resulted in increased inbreeding levels (Kearney et al., 2004). The decreased genetic variability and decreased production performance, known as inbreeding depression, are related to increased inbreeding levels (Falconer and Mackay, 1996; Smith et al., 1998). According to Carrillo and Siewerdt (2010), inbreeding depression is the decreased heterozygosis combined with the negative consequence of homozygosis in some locus, which directly affects the ability of using the genetic effects of direct dominance.

Several studies have presented unfavorable relationships between production and reproduction traits of cattle with inbreeding (Cassell et al., 2003; Panetto et al., 2010; Reis Filho et al., 2015). Moreover, according to Kearney et al. (2004), inbreeding increases genetic disorders, such as bovine leukocyte adhesion deficiency (BLAD) and complex vertebral malformation disease (CVM), and may limit the efficiency of genetic selection because of the decrease in genetic variability.

The regression of the phenotypic performances of the animal on the inbreeding coefficients has been used to estimate the inbreeding depression effects on traits of economic interest (Croquet et al., 2007). Ralls et al. (1988) showed that both linear and exponential models fit the data equally well, as long as the inbreeding levels are low to moderate. Due to the usually limited range of inbreeding coefficients in livestock populations, non-linearity is difficult to detect (Kristensen and Sorensen, 2005). However, linear regression model is commonly used in studies that explain the relationship between animal performance and inbreeding (Carrillo and Siewerdt, 2010; Panetto et al., 2010).

Studies on inbreeding depression in Holstein cows were performed using populations raised in temperate climate (Mc Parland et al., 2009; Rokouei et al., 2010; Dadar et al., 2014) under different management and production systems. Studies about the inbreeding effects on milk production traits in tropical climate animals were carried out by Soares et al. (2011) and Pryce et al. (2014) using Holstein and Jersey dairy cows in Brazil and Australia, respectively. Thus, information on the effect of inbreeding depression on production and reproduction traits in Holstein animals raised in tropical climate is essential for breeders because of possible consequences of increasing inbreeding in their herds.

The objective of the present study was to evaluate the effect of inbreeding depression on reproduction and production traits of Holstein cows by using four different regression models: linear, exponential, quadratic, and the Michaelis-Menten.

\section{Material and Methods}

The data used were provided by the Associação Brasileira de Criadores de Bovinos da Raça Holandesa (ABCBRH). The database was composed of pedigree information of 204,511 animals; 35,652 records of 305-day milk production (MP); 22,033 records of age at first calving (AFC); and 22,085 records of calving intervals (CI) in herds from the South and Southeast regions of Brazil (Table 1).

Pedigree and inbreeding estimation analyses were performed using the ENDOG 4.6 program (Gutiérrez and Goyache, 2005). The inbreeding coefficient (F) was calculated using the algorithm proposed by Meuwissen and Luo (1992). Inbreeding depression was analyzed using data of animals with at least 2.5 known equivalent generations.

Table 1 - Descriptive statistics of age at first calving (AFC), calving interval (CI), and 305-day milk production (MP) of Holstein cows in Brazil

\begin{tabular}{lccccc}
\hline Trait & $\mathrm{N}$ & $\mathrm{Mean}$ & Standard deviation & Minimum & Maximum \\
\hline AFC (days) & 22,033 & 804.43 & 119.72 & 594 & 1.475 \\
CI (days) & 22,085 & 444.03 & 110.07 & 300 & 1.373 \\
MP (kg) & 35,652 & $9,113.17$ & $2,338.36$ & $1,619.3$ & $16,467.5$ \\
\hline
\end{tabular}


The contemporary groups were composed of animals from the same herd, year of birth, and calving season (January to March, April to June, July to September, and October to December). Breeding values were predicted using an animal model with an individual analysis for each evaluated trait.

The effect of inbreeding on the study traits of Holsteins was determined by adjusting four regression models based on errors generated in the analysis of the animal model, as described by Carrillo and Siewerdt (2010). The general form of these regression equations is: $e_{i}=\Phi\left(F_{i}\right)+\varepsilon_{i}$ and $e_{i}=y-X \beta-Z_{1} a$, in which $e_{i}$ is the estimated errors in the vector; $\Phi\left(F_{i}\right)$ is the estimation of the regression function on the animal inbreeding $\left(\mathrm{F}_{\mathrm{x}}\right) ; \varepsilon_{i}$ is the deviations from prediction errors in the regression function; $X$ is the incidence matrix of fixed effects; $\beta$ is the solution vectors of the fixed effects; $Z_{1}$ is the incidence matrix of the additive direct genetic random effects; and $a$ is the solution vectors of the additive direct genetic effect.

The regression models evaluated were: linear $\left(e_{i}=\beta_{0}+\beta_{1}\left(F_{i}-\bar{F}\right)+\varepsilon_{i}\right)$, quadratic $\left(e_{i}=\beta_{0}+\beta_{1}\left(F_{i}-\bar{F}\right)+\beta_{2}\right.$ $\left.\left(F_{i}-\bar{F}\right)^{2}+\varepsilon_{i}\right)$, exponential $\left(e_{i}=\alpha \beta^{F i}+\varepsilon_{i}\right)$, and Michaelis-Menten $\left(e_{i}=\frac{\beta_{1}\left(1-F_{i}\right)}{\beta_{2}+\left(1-F_{i}\right)}+\varepsilon_{i}\right)$. Residual variances were compared as adjustment adequacy measures.

\section{Results}

The mean $\mathrm{F}$ of the Holstein cattle evaluated was $0.17 \%$, considering the animals with at least 2.5 equivalent generations (35,652 individuals). The mean $\mathrm{F}$ of the inbred animals (847 animals) was $6.02 \%$, with only 22 individuals presenting $\mathrm{F}$ above $20 \%$ (Figure 1 ).

The descriptive statistics of MP, AFC, and $\mathrm{CI}$ is presented in Table 1.

The residual variances for the linear, exponential, and Michaelis-Menten models were similar, ranging from $6,275.7$ to $6,279.8$ for $\mathrm{AFC} ; 7,355.3$ to $7,374.8$ for $\mathrm{CI}$; and 1,121,893.0 to 1,121,906.0 for MP. The quadratic model had values slightly different when compared with the other evaluated models, presenting 6,151.2 for AFC; 7,249.3 for CI; and 1,122,115 for MP.

The inbreeding effect on a trait can be studied by the regression coefficients from the models. The coefficient of regression of the inbreeding on MP presented significance $(P<0.05)$ only for the Michaelis-Menten and exponential models (Table 2). All evaluated models were significant $(\mathrm{P}<0.05)$ for CI (Table 2). Contrastingly, only the linear model was nor significant for AFC.

The adjustment of the exponential and Michaelis-Menten models was constant along the inbreeding levels (Figure 2). Cows with $\mathrm{F}$ value of $15 \%$ produced approximately 2 to $9 \mathrm{~kg}$ less milk than $5 \%$ inbred cows.

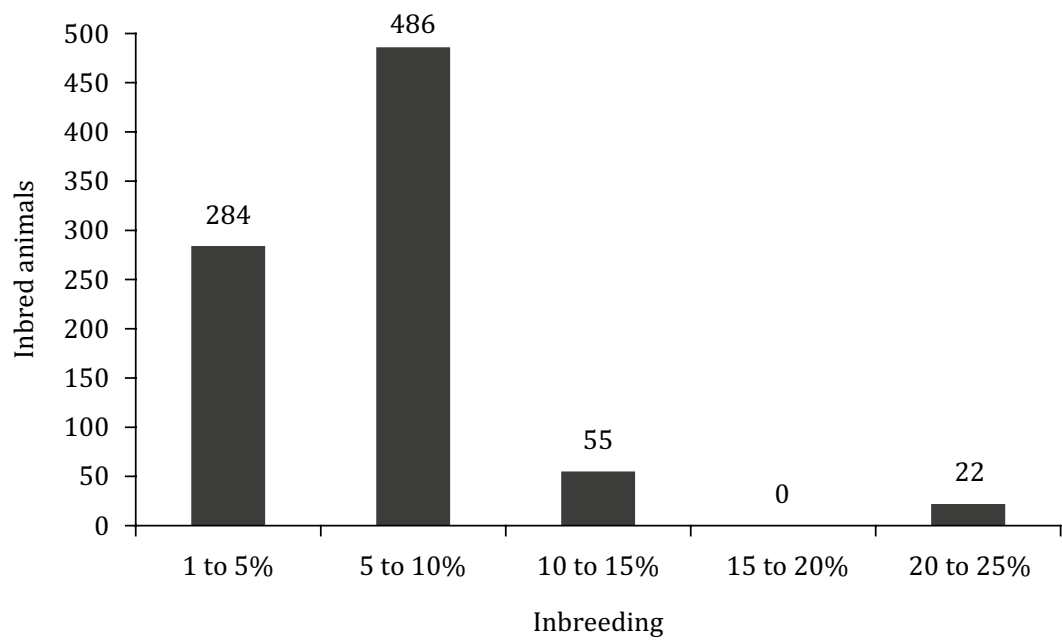

Figure 1 - Distribution by individual inbreeding class of the inbred Holstein cows in Brazil. 
The quadratic, Michaelis-Menten, and exponential models were significant $(\mathrm{P}<0.05)$ for AFC. The quadratic model showed an unfavorable effect of inbreeding on AFC, which increased with increasing inbreeding (Figure 3). The Michaelis-Menten and exponential models showed no variations in AFC with increasing inbreeding levels (Figure 3).

Table 2 - Estimates of regression coefficients of 305-day milk production (MP), age at first calving (AFC), and calving interval (CI) of the Holstein cows in Brazil

\begin{tabular}{|c|c|c|c|c|}
\hline Trait & \multicolumn{4}{|c|}{ Model } \\
\hline MP & $\begin{array}{c}\beta_{0}=8753.9781^{* * *} \\
\beta_{1}=87.9988^{\mathrm{ns}}\end{array}$ & $\begin{array}{c}\alpha=8754.0 \\
\beta=1.010^{* * *}\end{array}$ & $\begin{array}{c}\beta_{0}=8666.621^{* * *} \\
\beta_{1}=2337.531^{\mathrm{ns}} \\
\beta_{2}=-9037.11650^{\mathrm{ns}}\end{array}$ & $\begin{array}{c}\beta_{1}=8739.6 \\
\beta_{2}=-0.00212^{* * *}\end{array}$ \\
\hline $\mathrm{AFC}$ & $\begin{array}{c}\beta_{0}=804.29464^{* * *} \\
\beta_{1}=54.8139^{\mathrm{ns}}\end{array}$ & $\begin{array}{c}\alpha=804.4 \\
\beta=1.068^{* * *}\end{array}$ & $\begin{array}{c}\beta_{0}=775.1064^{* * *} \\
\beta_{1}=835.0113^{* * *} \\
\beta_{2}=-3234.9233^{* * *}\end{array}$ & $\begin{array}{c}\beta_{1}=786.3 \\
\beta_{2}=-0.0247^{* * *}\end{array}$ \\
\hline CI & $\begin{array}{c}\beta_{0}=425.6902^{* * *} \\
\beta_{1}=188.5248^{*}\end{array}$ & $\begin{array}{c}\alpha=426.6 \\
\beta=1.4952^{* * *}\end{array}$ & $\begin{array}{c}\beta_{0}=393.5506^{* * *} \\
\beta_{1}=990.5211^{* * *} \\
\beta_{2}=-3151.9353^{* *}\end{array}$ & $\begin{array}{c}\beta_{1}=345.6 \\
\beta_{2}=-0.1963^{* * *}\end{array}$ \\
\hline
\end{tabular}

ns $=$ not significant

${ }^{*} \mathrm{P}<0.05 ;{ }^{*} \mathrm{P}<0.01 ;{ }^{* * *} \mathrm{P}<0.001$

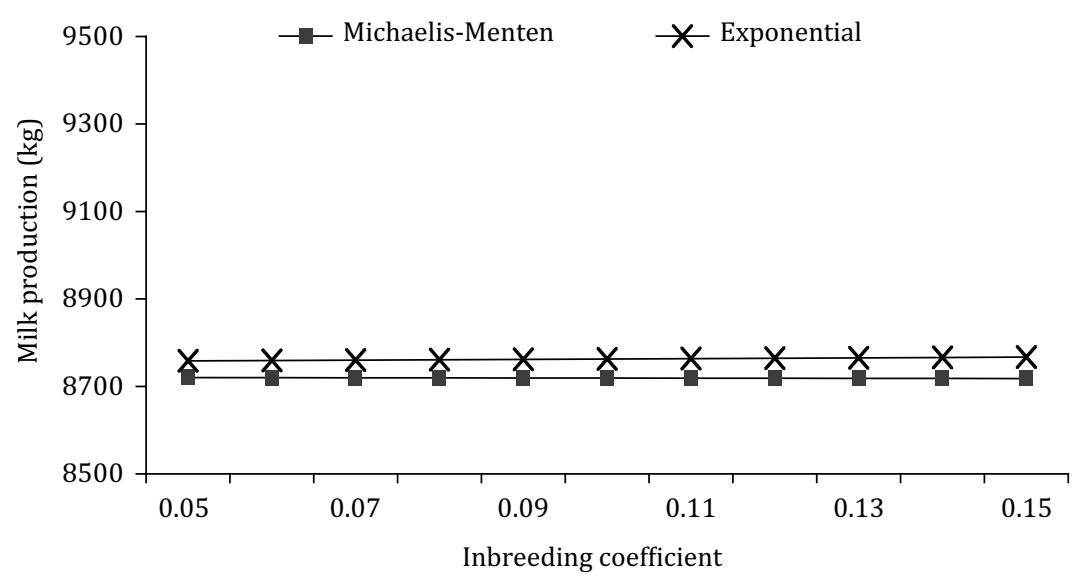

Figure 2 - Effect of inbreeding depression on the 305-day milk production of Holstein cows in Brazil.

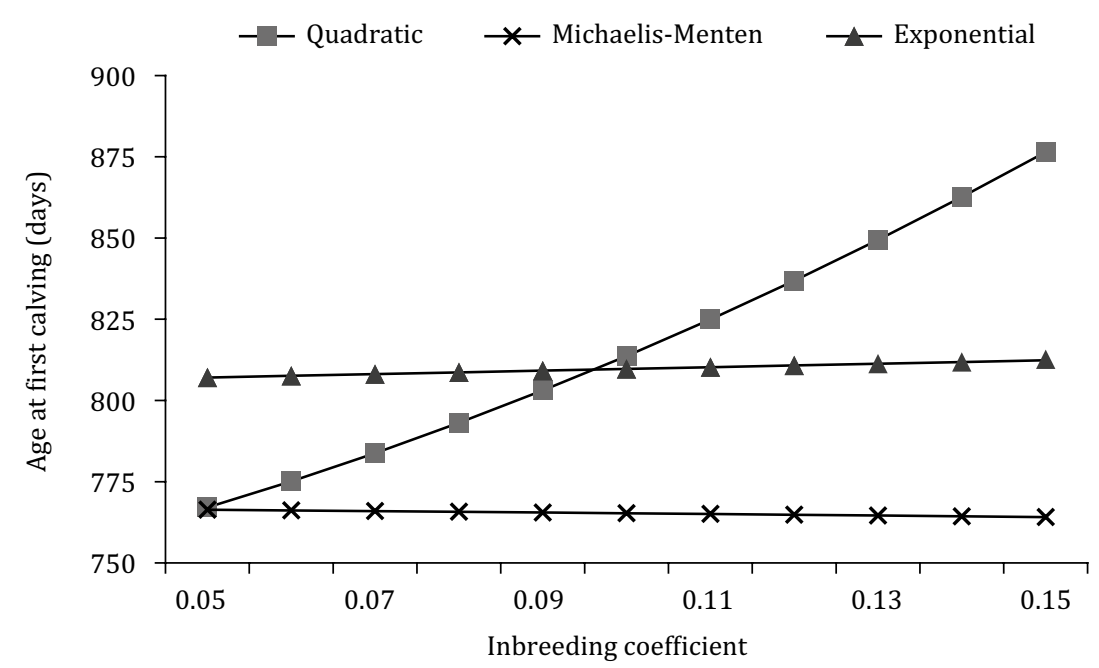

Figure 3 - Effect of inbreeding depression on age at first calving of Holstein cows in Brazil. 
The adjustments of the linear and exponential models were similar along the different inbreeding levels (Figure 4); Holsten cows with F of $15 \%$ had approximately 18 more days in CI than animals with $\mathrm{F}$ of $5 \%$. The Michaelis-Menten model was constant along the inbreeding levels; animals with $\mathrm{F}$ of $15 \%$ presented 0.85 less days in $\mathrm{CI}$ than those with $\mathrm{F}$ of $5 \%$.

\section{Discussion}

The mean inbreeding $(\mathrm{F}=0.17 \%)$ of animals with at least 2.5 equivalent generations and the mean $\mathrm{F}$ of inbred animals $(6.02 \%)$ indicate that the subpopulation was relatively large and was not closed (i.e., external genetics have been used by long period of time).

According to Silva et al. (2016), a small F value may indicate that few bulls were used intensively, probably due a more balanced use. These factors result in insufficient information of the ancestry and consequently, underestimation of F; therefore, the mean F decreases for inbred animals evaluated over 12 generations.

The results of mean MP $(9,133 \pm 2,338 \mathrm{~kg})$ were higher than that found by Campos et al. (2012) in a study on Holstein cows in Brazil $(8,415 \pm 1,910 \mathrm{~kg})$. The mean MP in Brazil has grown significantly over the last decades (Dürr et al., 2011), from 4,521 kg in 1985 (Boligon et al., 2005) to approximately 8,500 kg in 2015 (Campos et al., 2015; APCBRH, 2017). The increased mean MP per Holstein cows in Brazil is a result of improvements in nutritional management systems and application of technology for effective use of animals with greater genetic merit.

The mean age of the cows at first calving (approximately 26.43 months) indicated that heifers are being bred around 17 months of age; this is satisfactory for production systems under tropical climate conditions. McManus et al. (2008) observed higher AFC (910.10 \pm 204.86 days) in Holstein cows in the Center-West region of Brazil. The mean CI (14.80 months) indicates the possibility of decreasing the CI through improvements in nutritional and environmental managements.

The linear, exponential, and Michaelis-Menten models showed small differences in residual variances; similar values of residual variance indicate similar adjustments to the models evaluated (Malhado et al. 2013). According to Panetto et al. (2010), the minimum and maximum values of the evaluated traits can affect the values of residual variance; they reported that cows with high AFC tend to have an increased residual variance, but this does not efficiently represent animal productions.

The effect of inbreeding on the traits of interest is usually found by the estimates of the inbreeding regression coefficients. This is obtained with the application of different models on the evaluated traits. The linear correlation between inbreeding and production traits is based on the partial dominance (Carolino and Gama, 2008) and also in overdominance theory, which considers the loss of heterozygosis

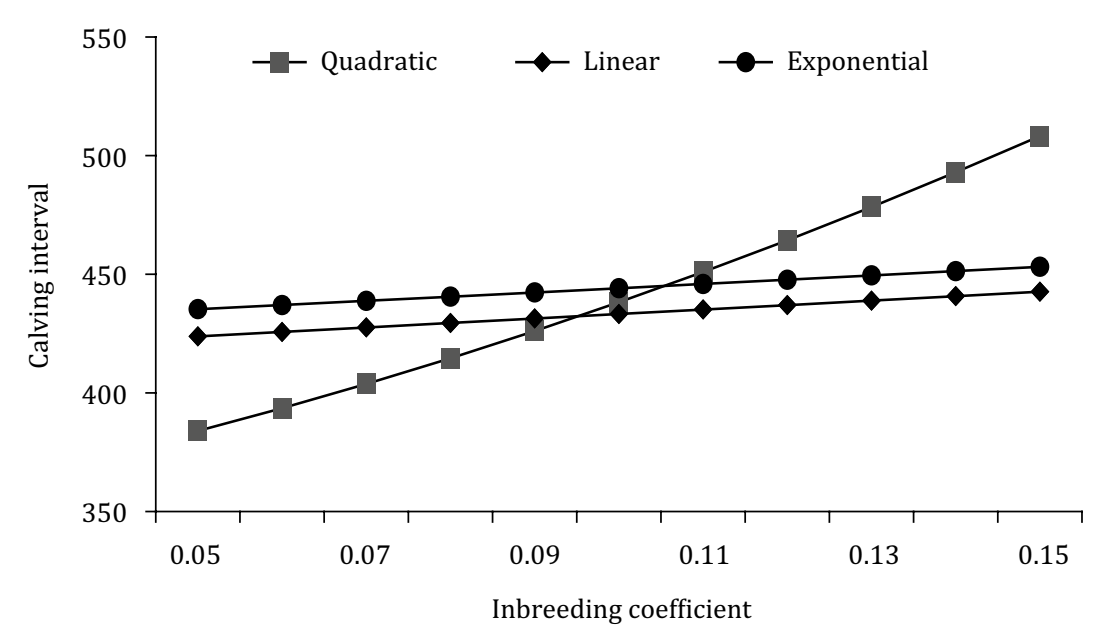

Figure 4 - Effect of inbreeding depression on calving interval of Holstein cows in Brazil. 
and an increase in the frequency of deleterious recessive homozygotes. However, a nonlinear decrease in the mean value of a trait with increasing inbreeding indicates the involvement of epistasis in the inbreeding depression of this trait (Charlesworth and Charlesworth, 1999). According to Kristensen and Sorensen (2005), this hinders the interpretation of this relationship due to the presence of different elements that are not directly connected to inbreeding.

The inbreeding regression coefficient of MP was not significant for the linear and quadratic models. However, Malhado et al. (2013) used a similar methodology for inbreeding depression and its effects on production and reproduction traits of Murrah buffaloes and found that the four models (linear, quadratic, Michaelis-Menten, and exponential) were significant $(\mathrm{P}<0.05)$ for MP.

The quadratic model has been widely used in studies on the relationship between inbreeding and production and reproduction traits (Mc Parland et al., 2007; Carolino and Gama, 2008; Casellas et al., 2009; Carrillo and Siewerd, 2010). However, Carolino and Gama (2008) found non-significant quadratic effect for 15 traits of economic interest in beef cattle. Studies on Holstein cows reported a significant effect of the quadratic model for eight out of 17 conformation (type) traits and for two management and three reproduction traits (Mc Parland et al., 2007).

According to Malhado et al. (2013), the linear model provides only a reasonable approximation of the phenomenon when using lower inbreeding levels. When inbreeding is greater than $20 \%$, the Michaelis-Menten model showed greater inbreeding depression for MP, lactation period, AFC, and CI of Murrah buffaloes, indicating the non-linearity effect. Carrillo and Siewerdt (2010) also reported that the Michaelis-Menten model had a more precise representation of the occurrence of inbreeding depression under higher inbreeding levels in the population.

The inbreeding regression coefficient for reproduction traits was not significant only for AFC evaluated with the linear model. Malhado et al. (2013) also found no significant effect of the linear model on AFC or CI of female buffaloes, but the results showed a significant effect of the exponential and MichaelisMenten models for these two traits.

Reis Filho et al. (2015) studied Gyr cows and included F in an animal model to test its linear and linear and quadratic effects. The authors observed that the model with the linear and quadratic effect of $\mathrm{F}$ was better adjusted for AFC and $\mathrm{CI}$ than the model with only the linear effect.

The exponential and Michaelis-Menten models showed low effect of inbreeding depression on MP (Figure 2), considering the different inbreeding levels. Croquet et al. (2007) reported different inbreeding depression for MP of Holstein cows with linear, quadratic, and cubic regression models, according to inbreeding levels; this denotes that inbreeding coefficients from 0 to $10 \%$ result in small differences between the three models. However, with the F value ranging from 6 to $10 \%$, the inbreeding depression in the cubic regression model was higher than that found with the other models (Croquet et al., 2007).

Milk production almost did not decrease with the increase of F value (Figure 2). Mc Parland et al. (2009) used a linear model for Holstein cows and found a decrease of $8.85 \mathrm{~kg}$ in MP for each $1 \%$ increase in the F level. Moreover, Thompson et al. (2000) used the linear model and found a decrease of $55 \mathrm{~kg}$ in MP of Holstein cows with inbreeding higher than 7.0\%.

The increase in F increased AFC of Holstein cows in Brazil when adjusted for the quadratic model (Figure 3).

Positive effects of inbreeding on AFC were found in female Murrah buffaloes (Malhado et al., 2013). Conversely, some studies have reported a negative effect of inbreeding on AFC; for example, Mc Parland et al. (2007) reported an increase of 2.5 days in AFC of Holstein cows with endogamy value of $12.5 \%$. In addition, Rokouei et al. (2010) evaluated populations of Holstein cattle in Iran and found a negative effect of inbreeding on AFC; it increased AFC in 0.45 days for each $1 \%$ increase in the inbreeding level. According to Thompson et al. (2000), inbreeding levels above $10 \%$ are connected with higher AFC in the Holstein breed, and inbreeding levels below 7\% appear to be connected with lower AFC, representing three to five days less in AFC when compared with non-inbred animals. 
The increase in inbreeding level affected CI of the animals. Similar to that observed for AFC, the quadratic model showed a significant effect of inbreeding on CI. Mc Parland et al. (2007) also reported negative effects of inbreeding on CI of Holstein cows when using the linear model; they found that inbreeding depression increased $\mathrm{CI}$ in 0.7 days for each $1 \%$ increase in inbreeding level. Rokouei et al. (2010) evaluated Holstein cows at first and second lactation in Iran and found no increase in CI with increasing inbreeding levels. However, they found a significant effect on $\mathrm{CI}$ in cows at third lactation, with increase of 0.53 days for each $1 \%$ of increase in the inbreeding level. Panetto et al. (2010) reported effects of inbreeding depression on AFC and CI in Guzerá cattle in Brazil.

This divergent results and difficulty in choosing models that best represent the effect of inbreeding are found among several previous studies (Croquet et al., 2007; Carrillo and Siewerdt, 2010; Reis et al., 2015 and Malhado et al., 2013). It may indicate an uncertainty about the choice of a model that best fits the complex biological effect of inbreeding on reproduction and production traits.

Losses due to inbreeding may differ according to population, environment, management, breeding systems, and traits of the evaluated animals (Leroy, 2014). Leroy (2014) reported a larger decrease in production traits than in other trait categories such as reproduction, survival, conformation, weight, and growth. DeRose and Roff (1999) reported that traits connected to survival, production longevity, fertility, and resistance to diseases present greater losses with increasing inbreeding level compared with morphological traits such as conformation traits in dairy cattle.

According to Carolino and Gama (2008), greater losses in economic traits due to inbreeding is expected for animals of pure lineages raised under intensive systems than for those from commercial herds under extensive systems and subject to low selection level. This may partially explain the results observed in this population which is of commercial herds (Silva et al., 2016) with low selection level.

Inbreeding depression leads to increased homozygosity in animals, which can cause lower fitness of the individuals to recessive detrimental mutations, besides decreasing the loci with heterozygous advantage (Charlesworth and Willis, 2009; Malhado et al., 2013). The frequent linear association between endogamy and animal traits is compatible with the dominance hypothesis, denoted by the loss of heterozygosis and increase of deleterious recessive homozygotes as inbreeding increases, ignoring the epistatic effect (Carolino and Gama, 2008).

The constant monitoring of the inbreeding levels is important to prevent problems such as inbreeding depression. The misuse of animal mating techniques in selection programs may contribute to increase inbreeding levels above the acceptable limits.

\section{Conclusions}

Brazilian Holstein cattle present low levels of inbreeding; however, some animals have surpassed the acceptable levels considered critical. According to most models, inbreeding level have no negative effect on milk production, calving intervals, and age at first calving of the evaluated population (commercial herds with low selection level). Among the four models evaluated, only the quadratic model presents the effect of inbreeding depression on calving interval and age at first calving.

\section{Conflict of Interest}

The authors declare no conflict of interest.

\section{Author Contributions}

Conceptualization: M.H.M.A. Silva, C.H.M. Malhado, E.L. Kern, D.S. Daltro, J.A. Cobuci and P.L.S. Carneiro. Data curation: M.H.M.A. Silva. Formal analysis: M.H.M.A. Silva, C.H.M. Malhado, E.L. Kern, D.S. Daltro, J.A. Cobuci and P.L.S. Carneiro. Investigation: M.H.M.A. Silva, C.H.M. Malhado, J.A. Cobuci 
and P.L.S. Carneiro. Methodology: M.H.M.A. Silva, C.H.M. Malhado, E.L. Kern, D.S. Daltro, J.A. Cobuci and P.L.S. Carneiro. Project administration: M.H.M.A. Silva. Supervision: C.H.M. Malhado, J.A. Cobuci and P.L.S. Carneiro.

\section{Acknowledgments}

The authors thank Embrapa Gado de Leite and the Associação Brasileira de Criadores de Bovinos da Raça Holandesa (ABCBRH) for providing the data used in this study; Dr. Claudio Napolis Costa, for his contributions; Conselho Nacional de Desenvolvimento Científico e Tecnológico (CNPq), for granting scholarships to professors Paulo Luiz Souza Carneiro, Jaime Araújo Cobuci, and Carlos Henrique Mendes Malhado; and Coordenação de Aperfeiçoamento de Pessoal de Nível Superior - Brasil (CAPES), for funding part of this study - Finance Code 001.

\section{References}

APCBRH - Associação Paranaense de Criadores de Bovinos da Raça Holandesa. 2017. Relatórios anuais. Available at: <http://www.apcbrh.com.br/apcbrh/relatorio-anual>. Accessed on: Mar. 05, 2017.

Boligon, A. A.; Rorato, P. R. N.; Ferreira, G. B. B.; Weber, T.; Kippert, C. J. and Andreazza, J. 2005. Herdabilidade e tendência genética para as produções de leite e de gordura em rebanhos da raça Holandesa no estado do Rio Grande do Sul. Revista Brasileira de Zootecnia 34:1512-1518. https://doi.org/10.1590/S1516-35982005000500011

Campos, R. V.; Cobuci, J. A.; Kern, E. L.; Costa, C. N. and McManus, C. M. 2015. Genetic parameters for linear type traits and milk, fat, and protein production in Holstein cows in Brazil. Asian-Australasian Journal of Animal Sciences 28:476-484 https://doi.org/10.5713/ajas.14.0288

Campos, R. V.; Cobuci, A. J.; Costa, N. C. and Braccini Neto, J. 2012. Genetic parameters for type traits in Holstein cows in Brazil. Revista Brasileira de Zootecnia 41:2150-2161. https://doi.org/10.1590/S1516-35982012001000003

Carolino, N. and Gama, L. T. 2008. Inbreeding depression on beef cattle traits: estimates, linearity of effects and heterogeneity among sire-families. Genetics Selection Evolution 40:511-527. https://doi.org/10.1051/gse:2008018

Carrillo, J. A. and Siewerdt, F. 2010. Consequences of long-term inbreeding accumulation on preweaning traits in a closed nucleus Angus herd. Journal of Animal Science 88:87-95. https://doi.org/10.2527/jas.2009-1897

Cassell, B. G.; Adamec, V. and Pearson, R. E. 2003. Effect of incomplete pedigrees on estimates of inbreeding and inbreeding depression for days to first service and summit milk yield in Holsteins and Jerseys. Journal of Dairy Science 86:2967-2976. https://doi.org/10.3168/jds.S0022-0302(03)73894-6

Casellas, J.; Piedrafita, J.; Caja, G. and Varona, L. 2009. Analysis of founder-specific inbreeding depression on birth weight in Ripollesa lambs. Journal of Animal Science 87:72-79. https://doi.org/10.2527/jas.2008-0897

Charlesworth, B. and Charlesworth, D. 1999. The genetic basis of inbreeding depression. Genetic Research 74:329-340. https://doi.org/10.1017/S0016672399004152

Charlesworth, D. and Willis, J. H. 2009. The genetics of inbreeding depression. Nature Reviews Genetics 10:783-796. https://doi.org/10.1038/nrg2664

Croquet, C.; Mayeres, P.; Gillon, A.; Hammami, H.; Soyeurt, H.; Vanderick, S. and Gengler, N. 2007. Linear and curvilinear effects of inbreeding on production traits for Walloon Holstein cows. Journal of Dairy Science 90:465-471. https://doi.org/10.3168/jds.S0022-0302(07)72648-6

Dadar, M.; Mahyari, S. A.; Rokouei, M. and Edriss, M. A. 2014. Rates of inbreeding and genetic diversity in Iranian Holstein Cattle. Animal Science Journal 85:888-894. https://doi.org/10.1111/asj.12228

DeRose, M. A. and Roff, D. A. 1999. A comparison of inbreeding depression in life-history and morphological traits in animals. Evolution 53:1288-1292. https://doi.org/10.1111/j.1558-5646.1999.tb04541.x

Dürr, J. W.; Ribas, N. P.; Costa, C. N.; Horst, J. A. and Bondan, C. 2011. Milk recording as an indispensable procedure to assure milk quality. Revista Brasileira de Zootecnia 40:76-81.

Falconer, D. S. and Mackay, T. F. C. 1996. Introduction to quantitative genetics. 4th ed. Longman, Harlow.

Gutiérrez, J. P. and Goyache, F. 2005. A note on ENDOG: a computer program for analysing pedigree information. Journal of Animal Breeding and Genetics 122:172-176. https://doi.org/10.1111/j.1439-0388.2005.00512.x

Jones, D. F. 1917. Dominance of linked factors as a means of accounting for heterosis. Genetics 2:466-479.

Leroy, G. 2014. Inbreeding depression in livestock species: review and meta-analysis. Animal Genetics 45:618-628. https://doi.org/10.1111/age.12178

R. Bras. Zootec., 48:e20170212, 2019 
Kearney, J. F.; Wall, E.; Villanueva, B. and Coffery, M. P. 2004. Inbreeding trends and application of optimized selection in the UK Holstein population. Journal of Dairy Science 87:3503-3509. https://doi.org/10.3168/jds.S0022-0302(04)73485-2

Kristensen, T. N. and Sorensen, A. C. 2005. Inbreeding - lessons from animal breeding, evolutionary biology and conservation genetics. Animal Science 80:121-133. https://doi.org/10.1079/ASC41960121

Malhado, C. H. M.; Malhado, A. C. M.; Carneiro, P. L. S.; Ramos, A. A.; Carrilo, J. A. and Pala, A. 2013. Inbreeding depression on production and reproduction traits of buffaloes from Brazil. Animal Science Journal 84:289-295. https://doi.org/10.1111/asj.12006

McManus, C.; Louvandini, H.; Falcão, R. A.; Garcia, J. A. S. and Saueressing, M. G. 2008. Parâmetros reprodutivos para gado Holandês em confinamento total no Centro-Oeste do Brasil. Ciência Animal Brasileira 9:272-283.

Mc Parland, S.; Kearney, J. F.; Rath, M. and Berry, D. P. 2007. Inbreeding effects on milk production, calving performance, fertility, and conformation in Irish Holstein-Friesians. Journal of Dairy Science 90:4411-4419. https://doi.org/10.3168/ jds.2007-0227

Mc Parland, S.; Kearney, F. and Berry, D. P. 2009. Purging of inbreeding depression within the Isish Holstein-Friesian population. Genetics Selection Evolution 41:16. https://doi.org/10.1186/1297-9686-41-16

Meuwissen, T. H. E. and Luo, Z. 1992. Computing inbreeding coefficients in large populations. Genetics Selection Evolution 24:305-313. https://doi.org/10.1186/1297-9686-24-4-305

Panetto, J. C. C.; Gutiérrez, J. P.; Ferraz, J. B. S.; Cunha, D. G. and Golden, B. L. 2010. Assessment of inbreeding depression in a Guzerat dairy herd: Effects of individual increase in inbreeding coefficients on production and reproduction. Journal of Dairy Science 93:4902-4912. https://doi.org/10.3168/jds.2010-3197

Pryce, J. E.; Haile-Mariam, M.; Goddard M. E. and Hayes, B. J. 2014. Identification of genomic regions associated with inbreeding depression in Holstein and Jersey dairy cattle. Genetics Selection Evolution 46:71 https://doi.org/10.1186/ s12711-014-0071-7

Ralls, K.; Ballou, J. D. and Templeton, A. 1988. Estimates of lethal equivalents and the cost of inbreeding in mammals. Conservation Biology 2:185-193. https://doi.org/10.1111/j.1523-1739.1988.tb00169.x

Reis Filho, J. C.; Verneque, R. S.; Torres, R. A.; Lopes, P. S.; Raidan, F. S. S. and Toral, F. L. B. 2015. Inbreeding on productive and reproductive traits of dairy Gyr cattle. Revista Brasileira de Zootecnia 44:174-179. https://doi.org/10.1590/S180692902015000500002

Rokouei, M.; Vaez Torshizi, R.; Moradi Shahrbabak, M.; Sargolzaei, M. and Sørensen, A. C. 2010. Monitoring inbreeding trends and inbreeding depression for economically important traits of Holstein cattle in Iran. Journal of Dairy Science 93:3294-3302. https://doi.org/10.3168/jds.2009-2748

Silva, M. H. M. A.; Machado, C. H.; Costa Jr, J. L.; Cobuci, A. J.; Costa, C. N. and Carneiro, P. L. S. 2016. Population genetic structure in the Holstein breed in Brazil. Tropical Animal Health Production 48:331-336. https://doi.org/10.1007/ s11250-015-0956-7

Smith, L. A.; Cassel, B. G. and Pearson, R. E. 1998. The effects of inbreeding on the lifetime performance of dairy cattle. Journal of Dairy Science 81:2729-2737. https://doi.org/10.3168/jds.S0022-0302(98)75830-8

Soares, M. P.; Gaya, L. G.; Lorentz, L. H.; Batistel, F.; Rovadoscki, G. A.; Ticiani, E.; Zabot, V.; Di Domenico, Q.; Madureira, A. P. and Pértile, S. F. N. 2011. Relationship between the magnitude of the inbreeding coefficient and milk traits in Holstein and Jersey dairy bull semen used in Brazil. Genetics and Molecular Research 10:1942-1947. https://doi.org/10.4238/ vol10-3gmr1010

Sørensen, A. C.; Sørensen, M. K. and Berg, P. 2005. Inbreeding in Danish dairy cattle breeds. Journal of Dairy Science 88:1865-1872. https://doi.org/10.3168/jds.S0022-0302(05)72861-7

Thompson, J. R.; Everett, R. W. and Hammerschmidt, N. L. 2000. Effects of inbreeding on production and survival in Holsteins. Journal of Dairy Science 83:1856-1864. https://doi.org/10.3168/jds.S0022-0302(00)75057-0 